sustentation has to be used in order to institute a comparison between theory and experiment. In Part II certain propositions which were first enunciated in the author's "Aerodynamics" are given.

Part IV, which contains the gist of the whole paper, is- devoted to a comparison instituted between. theory and recent data furnished by experiments conducted in the compressed air tunnel at the National Physical Laboratory (Aeronautical Research Committee: Reports and Memoranda, 1627). The essence of the matter is that prior to the installation of this tunnel, it was not possible to conduct wind channel experiments at high Reynolds' numbers such as apply in the case of full-scale machines, and it had long been known or at least suspected that there is a great difference between high and low Reynolds' numbers. The extent of the agreement (or disagreement) was a matter of conjecture. It is demonstrated that complete reliance may be placed on the predictions of theory under conditions of high Reynolds' numbers. The examples taken for the purpose of investigation are aerofoils R.A.F. 48, Clark $Y H$, and Göttingen 387 ; the results are given tabulated and as plottings.
In Part $V$ it is shown that in contrast to the agreement found over a range of high Reynolds' numbers (namely, about $2 \times 10^{6}$ and upwards) theory can no longer be considered reliable. For the full-scale glider or sail-plane where the Reynolds' number is in the region of $1.7 \times 10^{6}$, agreement is still good, but when the same methods are applied to the investigation of model aerofoils and gliders the discrepancies are shown to be considerable. The reasons for this are discussed.

In the four appendixes the more important matters are: A relation is established between the gross weight of an aeroplane and the Reynolds' number; and three diagrams are given, by the aid of which the Reynolds' number may be ascertained prior to design, if the projected gross weight and the aspect ratio are given. In Appendix III reference is made to the region of instability or uncertainty in the relations of $\mathbf{C}_{0}$ to the Reynolds' number, illustrated by plottings due to $\mathrm{Mr}$. G. Baker (1915) and Prof. Melvile Jones (Rep. and Mem., 1199). Appendix IV is devoted mainly to the aerodynamics of flying at high altitude.

\title{
A Magdalenian Site of Southern France: The Cave of Isturitz*
}

$\mathrm{N}$ continuation of the exploration of the palæolithic cave of Isturitz (Basses Pyrénées) by Dr. R. de Saint-Périer, of which the Magdalenian levels in the Hall of St. Martin have already been described (Arch. Inst. Pal. Hum. Mém., 7 ; 1930. See Nature, 128,$988 ; 1931$ ), the Magdalenian deposits of the adjoining Great Hall, or Hall of Isturitz, as it has been named, have now been excavated; and it has become possible to take a general view of the Magdalenian culture of the site as a whole.

The Magdalenian deposits overlie Solutrean and Aurignacian levels, which are now being examined, without the intervention of any sterile layers. It is evident that both the Solutrean and the Magdalenian tribes established themselves here without any independent stratigraphic formation taking place. Both halls were occupied at the time the earliest Magdalenian deposits were laid down; but it is apparent that the occupation of the Great Hall was both longer and more intense than that of the Hall of St. Martin. Hearths, however, in the Great Hall are less frequent. A further difference is that while engraved plaques are exceptional in the Great Hall, though there art blossoms into great richness, in the Hall of St. Martin such plaques are numerous.

Although the age of the Magdalenian is that of the older Magdalenian of the Pyrenees, it is not, even at the base levels, the oldest stage of that culture. As is shown by the character of the lanceheads and certain of the engravings, these lower levels belong to Magdalenian iii, corresponding to Marsoulas. Above this is the culture of Magdalenian iv ; but only in the Great Hall are found the harpoons, of which the evolved character points to a later occupation.

The most important period of occupation is Magdalenian iv, of which the chief characteristics are :

*Archives de l'Institut de Paléontologie Humaine. Mém. 17. La Grotte d'Isturitz. 2: Le Magdalénien de La Grande Salle. Par Dr. René de Saint-Périer. Pp. $140+12$ plates. (Paris: Masson et Cie., 1936.) $120 \mathrm{fr}$. a cold climate fauna, in which the horse is predominant, but a few retarded forms such as Rhinoceros tichorhinus, Ursus speloeus and Hycena crocuta survive; and a lithic industry which is small and of mediocre execution, the various forms being not clearly defined and many implements being made from irregular and bad flakes. Burins are dominant. The bone industry is abundant, especially in the Great Hall. Many used bones show little sign of preparation for their purpose. The bone objects include needles, lance-heads of diverse types, batons, etc. A large number of the artefacts have been treated under a single classification as 'perforated'. The prototypes of harpoons found in the Great Hall already show signs of evolution.

The art forms of this period are here fully represented. They occur indiscriminately from bottom to top of the deposits of the period without distinction as to the level in which they are found. As already mentioned, the art of the Great Hall is richly developed both in the naturalistic form and in the conventionalized decorative motives. The naturalistic art in both sculpture and engraving shows remarkable powers of accurate observation of animal forms; while the conventionalized designs are clearly based on an equally accurate observation of the natural forms from which they are derived. One remarkable piece of engraving on bone represents a scene between a man and woman, of which the pose and composition depict graphically an expression of intense desire on the part of the male. The head of the woman and the lower part of the man are missing. The artist appears to have intended to represent the woman as thickly covered with hair over a great part of her body.

The abundance of the examples of this art in the Great Hall must account for the fact that, although much of it is of the highest quality, as a whole it is uneven and the choice of material is sometimes bad. The inferior may represent trial and practice pieces. 
In the levels of Magdalenian $\mathrm{v}$ and vi the climate is still cold; but the horse is less abundant. For a time the reindeer is important and then gives way to the deer. Birds become abundant. There is no very marked change in the character of the stone industry; the bone artefacts show a characteristic 'fossil' in the form of a staghorn point with a forked base; barbed harpoons appear. Objects of art become scarcer; sculpture disappears, and the art form is reduced to simple graving. Both realist and decorative art weaken and are less varied.
In the material of this level, the Azilians made their hearth. The stone industry above the Magdalenian levels resumes the forms of the Aurignacian culture with characteristic delicacy and beauty of retouch. Circular scrapers determine the Azilian character of the culture, their evidence being confirmed by the harpoons, which become more and more evolved.

With the close of this period man's occupation of the cave, save for burial purposes, comes to an end.

\section{The British Institute of Radiology}

\section{Annual Congress and Exhibition}

$\mathrm{T}$ HE tenth Annual Congress and Exhibition of the British Institute of Radiology was held at the Central Hall, Westminster, on December 2-4, 1936. The arrangements differed to some extent from those of previous years, notably in the inclusion of a section of the exhibition devoted to physical research. Among the institutions represented in this section were St. Bartholomew's, the Royal Cancer and the Mount Vernon Hospitals, Radium Beam Therapy Research, and the National Physical Labora. tory, while Dr. Russell Reynolds showed an X-ray cinematograph apparatus. The section showed clearly the close connexion between physical research, even modern atomic physies, and the medical applications of radiations of all types. The exhibit of radium beam therapy research was concerned with a study of induced radioactivity, the principal item being a Geiger counter connected to a cathode ray oscillograph, the screen of which is photographed on a $35 \mathrm{~mm}$. ciné film operated by a mechanism so designed that the speed of motion of the film varies logarithmically with time. By the use of this device, the film moves quickly enough to record the rapid counts of a newly activated material but slows down as the activity decays, so that considerable economy in the cost of film results.

The Royal Cancer Hospital and the Mount Vernon Hospital had exhibits dealing with $\mathrm{X}$-ray and radium dosage, their measurement and typical results. The apparatus used at the Royal Cancer Hospital to determine the gamma-ray output of radium in röntgens consists of accurately made air-wall ioniza. tion chambers connected to a Lindemann electrometer, while the Mount Vernon Hospital exhibit included a valve amplifier of the DuBridge type working in conjunction with air-wall chambers and used for exploring the fields round radium sources.

The St. Bartholomew's Hospital exhibit included a demonstration of a simple form of Geiger counter employing a neon lamp for measuring weak beams of gamma-rays and locating missing radium containors, and also a series of photographic films illustrating the paths of alpha- and beta-rays in celluloid and in photographic emulsions.

The National Physical Laboratory showed, inter alia, transparencies illustrating the apparatus used in the standardization of X-ray and gamma-ray dosemeters and in the testing of radium containers, sensitive dosemeters for the measurement of stray radiation, and various $\mathrm{X}$-ray crystal photographs dealing with the structure of teeth, electro-plating, corrosion and fatigue in metals, etc. A further exhibit consisted of a model of a periscope for observing patients undergoing treatment with very penetrating radiations. The optical system comprises eight concave mirrors, but the system is so designed that, although the light beams fall on the mirrors at approximately $45^{\circ}$ to their normals, there is negligible distortion and the image appears normal size and nearer to the observer than the object.

The X-ray cinematograph equipment shown employs an indirect method in which the image on a fluorescent screen is photographed on $35-\mathrm{mm}$. ciné film, which has an emulsion specially developed to have a high sensitivity to the light emitted by the screen. In order to reduce the strain on the apparatus and the X-ray tube, an ingenious switch is incorporated so that the tube is only excited during actual exposure. The ciné camera is of the conventional type, fitted with a special lens operating at $f 0 \cdot 8$.

The session of the Congress devoted to physical and technical papers consisted in a symposium on "The Measurement of Tonization Current". Dr. D. E. Lea described a valve amplifier for the measurement of ionization currents which shares with the Townsend compensation method the advantage that the collecting electrode of the necessary ionization chamber is always substantially at earth potential. The ionization current is passed into a condenser connected to the grid of an electrometer triode the output of which is connected to two further stages of valve amplification, with the result that, in normal settings, a change of voltage of one millivolt on the grid of the electrometer valve brings about a change of voltage of ten volts in the output of the amplifier. The variation in the output voltage is thus sufficiently great to permit the operation of suitable relays and counting mechanisms through the intermediary of a thyratron. For the measurement of weak beams of radiations the rate of variation of the output voltage can be found over part of the full scale of the output voltmeter. By suitable adjustments the sensitivity of the instrument can be varied over a wide range.

Dr. G. W. C. Kaye, Mr. W. E. T. Perry and Mr. D. E. A. Jones described a ballistic amplifier in which troubles due to slow drifts and zero unsteadiness are avoided by isolating the detecting galvanometer from the anode circuit of the valve by the use of a blocking condenser. The apparatus may be used in two ways. In the first, the grid of the valve is 